Andrei $V$. Ivanov, Dr. of Philosophical Sciences, Professor Altai State Agrarian University (Barnaul, Russia) ivanov_a_v_58@mail.ru

Svetlana M. Zhouravlyova, Ph. D. of Philosophy Sciences, Associate Professor Altai State Agrarian University (Barnaul, Russia) jurav27@yandex.ru

\title{
THE BIG EURASIA: IDEA, CHALLENGES, GOALS OF RUSSIA AND SIBERIA
}

\author{
The reported study was funded by Russian Fund of Basic Research \\ and Social Research Expert Institute according to the research project no. 20-011-31304 \\ "Siberia for All Russia: the Essence and Mechanisms of Spiritual \\ and Ecological Civilizational Transformation"
}

\begin{abstract}
From the points of civilizational approach, the paper analyses shades of meaning of a geopolitical term Big Eurasia included into scientific lexicon after declaration made by Xi Jinping, acting General Secretary of the Chinese Communist Party, in Astana (Kazakhstan), 2013, in which he announced a new international project "Sink Road Economic Belt" aimed at creation of integrated Eurasian economic space and a system of transcontinental (by land (railroad) and by sea) corridors. According to authors' opinion, Big Eurasia includes megacivilizations of the East and the North (Inner or "little") Eurasia (with Russia that belongs to the last one) that both are going through an integration era. The article gives a list of key challenges and problems that states (China, Russia) trying to reach a leader status in regional integration processes face with. Also, the paper highlights current tasks of Russian and Siberia in large geopolitical projects run in Eurasia.
\end{abstract}

Keywords: Big Eurasia, North ("little") Eurasia, Russia, Siberia, megacivilization, integration, civilizational approach, project "Silk Road Economic Belt".

УДК 248.158:338.482.22

DOI: $10.32340 / 2414-9101-2020-3-20-33$

И. В. Леонов, доктор культурологии Санкт-Петербургский государственный институт культуры (Санкт-Петербург, Россия) ivaleon@mail.ru

И. В. Кириллов Санкт-Петербургский государственный институт культуры (Санкт-Петербург, Россия) os84@yandex.ru

А. О. Пиянтинов

Томский государственный университет (Томск, Россия), Совет Каракольской долины (Горно-Алтайск, Россия) piyantinov87@mail.ru

\section{САКРАЛЬНЫЕ АРТЕФАКТЫ КУЛЬТУРЫ И ПРОБЛЕМА ИХ ТИРАЖИРОВАНИЯ В СУВЕНИРНОЙ ПРОДУКЦИИ}

Аннотация. Проанализирована современная практика изготовления и распространения предметов сувенирной продукции, в основу которой положена эксплуатация элементов знаковосимвольного ряда сакральных артефактов различных этнических культур. Отмечены некоторые положительные и отрицательные аспекты массового производства сувениров, в конструктивном 
аспекте представляющих собой имитации художественных форм, воплощающих смыслы, заимствованные из ядра знаково-символьной системы священных объектов. Представлен краткий обзор истории эволюции феномена сувенирной продукции с XIX в. до наших дней. Изложена авторская оценка места сувенира в пространстве культуры повседневности, массовой культуры, в сфере туризма. Охарактеризована специфика этнотрадиционных сувениров.

Ключевые слова: артефакт, сакральное, сувенир, картина мира, культурогенез, культурное наследие, архетип.

Одним из распространённых явлений современной культуры являются сувениры. В современном мире вряд ли можно найти дом, где не было бы сувенирных изделий, подаренных хозяевам или приобретённых ими. Также достаточно часто сувениры украшают рабочие места, автомобили и сопровождают человека в качестве вещей повседневного обихода, которые находятся при нем почти постоянно; в журналах мод помещают рекомендации - при разработке дизайна интерьера квартиры заранее предусмотреть в ней полки для сувениров. Став практически непременным атрибутом современной жизни, сувениры нашли своё прочное место в пространстве культуры: в сфере подарков и развлечений, в индустрии туризма и других сегментах повседневной и праздничной жизни.

Самостоятельным направлением развития сувенирной отрасли является производство и тиражирование этносувенирной продукции, важнейшей функцией которой является напоминать о традиционном прошлом многих культур, а также сохранять некоторые традиционные аспекты культуры (пусть даже в несколько изменённом виде) и транслировать их последующим поколениям. В этом ракурсе сувениры, воспроизводящие традиционные (в том числе и сакральные) артефакты, могут быть восприняты как вполне уместные. С другой стороны, данная продукция, следуя вкусам и невысокому уровню этнокультурной грамотности массового потребителя, а также преследуя сугубо экономические цели и нередко претерпевая сильнейшие искажения, провоцирует неорганические трансформации и «разрывы» «наследственного генома» тех культур, которые она репрезентует [1, с. 97]; многие сувениры создаются на грани китча, им важно быть «замеченными и проданными» [2, с. 93]. В результате в рассматриваемой отрасли складывается противоречивая картина, когда массовый и достаточно эффективный канал трансляции традиционных аспектов культуры работает неэффективно, а порой и в ущерб гармоничной передаче наследственного материала той или иной культуры.

Одним из аспектов данной проблематики является производство и тиражирование в качестве этносувенирной продукции артефактов, которые относятся либо относились ранее к сфере сакральных. Равным образом данное замечание относится к тиражированию отдельных элементов сакральных артефактов либо воспроизводству на сувенирной продукции их образной и знаковосимволической стороны. В настоящее время в сувенирных лавках нередко можно встретить брелоки, посуду, чашки, шариковые ручки и т. п. изделия, воспроизводящие, имитирующие или отражающие формы либо образы предметов культа. При этом такие сувениры нередко могут сохранять для своих владельцев и сакральные стороны воспроизводимых феноменов. Порой в качестве сувенира могут быть воспроизведены артефакты, имеющие отношение к языческим, магическим и шаманским культам (например, шаманский бубен), право владения и пользования которыми исторически было ограничено по кругу лиц, а сакральный статус полностью открыт только посвящённым; кроме того, прямой контакт с такими артефактами сопровождался для общества многими табу. Отмеченная тенденция часто касается и предметов религиозного культа. Эти и многие другие примеры провоцируют неоднозначность восприятия такой продукции представителями различных культур, поколений и социальных групп.

Рассматривая данную проблематику, в первую очередь необходимо указать, что бытование сувениров в современной культуре имеет достаточно весомую предысторию и психоментальные основания. Названный феномен не сводим к его пониманию как масскультовой инно- 
вации, тиражируемой на низкокачественном уровне и ориентированной исключительно на экономический фактор.

Слово «сувенир» (от фр. souvenir) означает артефакт, призванный напоминать о ком-либо, о чём-либо; зачастую под сувениром понимают «художественное изделие, отдельные потребительские товары, отражающие национальные, природные, культурные и другие особенности страны, региона, города, посещаемых туристами, и приобретаемые ими на память или для подарка другим лицам» [3, с. 239]. У сувенира в первую очередь знаковая природа, он пробуждает в памяти определённые ситуации, напоминая о них. Это некая «зацепка памяти» (причём индивидуальной памяти [2, с. 42]), «ниточка», знак, обеспечивающий связь с прошлым, с каким-либо событием или с другим лицом, пробуждая их образы в памяти и возвращая в воображении ушедшую реальность; иными словами, посредством сувениров осуществляется «телесно организованная мнемотехника» $[4$, c. 40], позволяющая за счёт ассоциаций и связей увеличить объем памяти. Соответственно, смысловая или ассоциативная нагрузка сувенира как феномена, тесно сопряжённого с информационно-семиотической сердцевиной культуры $[5$, с. $70-71,76]$, не менее существенна, а порой и более значима, нежели его материальная форма. Забегая несколько вперёд, отметим, что «смысловая аура» многих сувениров может обретать для владельцев чрезвычайно большую значимость, в результате чего сувениры становятся для них «сакральными». В данном случае показательно мнение Т. Ю. Быстровой, которая указывает, что «сувенирами становятся, а не рождаются. Соответственно, если предмет теряет свой смысловой ореол, он дезактуализируется, теряя статус сувенира (ракушка может «превратиться» в вещество природы)» [6, с. 43].

Сувенирная продукция достаточно многообразна, что даёт почву для составления различных типологий. К примеру, классификация, предложенная Т. Ю. Быстровой и А. К. Хисматулиным, включает три группы. Первую из них составляют индивидуальные и групповые сувениры, причём последние, в свою очередь, подразделяются на профессиональные, конфессиональные и корпоративные. Вторая группа включает традиционалистические, классические, постнеклассические, информационные сувениры, создаваемые с ориентацией на разные ценностно-смысловые системы культуры. В последнюю группу входят пассивные, активные и интерактивные сувениры [7, c. 310]. В контексте данного исследования, с опорой на традицию Н.Я. Данилевского и О. Шпенглера, которые отстаивали индивидуальные и неповторимые черты каждого отдельного культурного типа и организма, представляется уместным сосредоточиться на таком типе сувенирной продукции (вполне самостоятельном, достаточно обособленном и качественно определённом) как этносувенир.

Феномен сувенирной продукции появился во второй половине XIX в.; его зарождение напрямую связано с модернизационными процессами, которые затронули в данный период многие культуры. Однако, как уже было указано выше, рассматриваемое явление имеет предысторию, глубокие корни, в том числе и архетипического характера. Всевозможные «памятки», «поминки» и т. п. - небольшие предметы, издревле бытовавшие в самых разных культурах, напоминавшие о каких-либо духовных или мирских явлениях и обеспечивавшие «связь» владельца с определённой сущностью, локацией, явлением, материальным объектом либо живым существом не принято, конечно, причислять к сувенирам в современном понимании этого термина, однако они явно находятся в родстве с рассматриваемым явлением. (Также необходимо отметить то, что в культурах западноевропейских стран корни сувениров уходят к религиозным паломничествам, прежде всего в Палестину и в Сантьяго-де-Компостела (Испания): паломники старались привезти из сакральных мест всевозможные мелкие предметы, полагая, что они наделены сверхестественной силой; уже в средневековье мастерские при христианских монастырях выделывали особые значки для продажи паломникам [8, с. 146-152]). Исторически человек проявлял свойство «опредмечивать» прошлое и настоящее; люди нуждались в материальных подтверждениях своей «исторической памяти», воспоминаний и психоэмоциональных переживаний (включая наиболее ценные из них). В результате тот или иной артефакт становился «ключом»к некой реальности, обретая значимый статус. 
Кроме того, в контексте рассматриваемого вопроса уместно обратиться к явлению фетишизма, которое стало, начиная с древнейшего периода истории, одной из форм взаимодействия с реальностью путём приписывания сверхъестественных способностей материальным предметам, в том числе обеспечения устойчивых связей и способов взаимодействия с самыми разными гранями бытия. Фетишистские проявления в отдалённом и несколько видоизменённом виде свойственны и некоторой части изучаемой сувенирной продукции. В данном случае показательно обилие сувениров, которые могут изначально создаваться, а также восприниматься массовым потребителем в качестве оберегов. Интерес представляет то, что в указанных феноменах, отголоски которых просматриваются в сувенирной продукции, проявляются различные функции, либо напрямую, либо косвенно связывающие их с сакральной составляющей культуры-nредмет воздействует на реальность и обеспечивает связи с другой реальностью; предмет оберегает; предмет дорог, он наделяется иенностно-смысловой значимостью. При этом сфера сакрального предстаёт как достаточно обособленная от обыденной и тривиальной составляющих культуры, что делает обращение к ней на уровне массового производства сувениров весьма противоречивым явлением.

Термин «сакральное» (от лат. sacrum-«посвященное богам», «священное», «запретное», «проклятое») означает «свойство, обладание которым ставит объект в положение исключительной значимости, непреходящей ценности и на этом основании требует благоговейного к нему отношения». Этимология слова во многом связана «со значением отделённости, сокрытости, неприкосновенности» [9, с. 839]; сакральное принципиально отличают от «обыденного», «профанного», в религиозных культурах сакральное воспринимается как абсолютная, вечная реальность, как субстанщия бытия. «В картине мира С. выполняет роль структурообразующего начала: в соответствии с представлениями о С. выстраиваются другие фрагменты картины мира и складывается их иерархия» $[10$, с. 440$]$. С наибольшей полнотой представления о сакральном выражаются в религиозном мировоззрении, поэтому нередко под сакральным понимают то, что относится к религиозному культу, обряду [11, с. 391; 12, с. 591], однако подобное суженное, «редуцированное» определение является не вполне верным, поскольку к категории сакрального относятся и многие языческие артефакты и явления (а для Нового и Новейшего времени характерна «сакрализация» некоторых мирских предметов, персон и явлений).

Рассмотренная суть сакрального рождает проблему воспроизводства связанных с ним артефактов в качестве сувениров, которые означают или «опредмечивают» то, что в своем абсолютном выражении имеет иную природу и не может быть формально произведено, растиражировано и внедрено в повседневный обиход на уровне обыденных вещей. Тем не менее, существует ряд обстоятельств, которые надо учесть при рассмотрении данной проблемы, а именно фактор разных степеней восприятия сакрального в современных культурах, то есть уровень его ценностносмысловой наполненности с точки зрения актуализации на сегодняшний день. Отмеченные степени могут достаточно существенно разниться как в отношении различных периодов культурогенеза, так и в пространстве различных социальных групп, ориентированных на те или иные ценностно-смысловые установки. В результате то, что исторически позиционировалось в конкретной культуре в качестве сакрального, может выступать для одних истинно сакральным и значимым, а для других выглядеть отголоском прошлых эпох, служить объектом проявления уважения к собственной культуре, выступать её внешним маркёром или основой для выражения собственной этнокультурной идентичности и т. п.; вплоть до того, что сфера сакрального определённой культуры, включая её исторические трансформации, может в принципе не восприниматься потребителем в силу отсутствия знаний об этом или в силу принадлежности к иным сакральномировоззренческим традициям.

Одним из существенных аспектов анализа распространения этносувенирной продукции, воспроизводящей в том числе и сакральные артефакты, является учёт такого маркера как выход многих культур из состояния «домодерна» в период модернизации (в основном соотносимый с Новейшим временем) - с соответствующим комплексом мировоззренческих изменений, влияющих и на рассматриваемый феномен. 
Для «домодерновых» культур был свойственен явно выраженный акцент на сакральную сторону реальности; люди домодерна обладали «космическим чувством», могли видеть сакральные смыслы во всех проявлениях бытия; заурядные повседневные акты-пахота, покос, трапеза и т. д. - зачастую приобретали для них литургическое значение. В Новое время в Европе культурная ситуация принципиально поменялась: проникнутое мифолого-религиозным сознанием общество было радикально трансформировано, что вызвало, в частности, коренное изменение отношения к сакральному. Впоследствии схожие явления произошли и в других регионах земного шара. Описывая разрушение «священных образов», К. Г. Юнг писал: «Бессознательные формы всегда получали выражение в защитных и целительных образах и тем самым выносились в лежащее за пределами души космическое пространство. Предпринятый Реформацией штурм образов буквально пробил брешь в защитной стене священных символов... История развития протестантизма является хроникой штурма образов. Одна стена падала за другой... Большие и малые, всеобщие и единичные, образы разбивались один за другим, пока наконец не пришла царствующая ныне ужасающая символическая нищета. Протестантское человечество вытолкнуто за пределы охранительных стен» [см.: 13, с. 133-152].

Для восполнения образовавшегося «духовного вакуума» современным обществом была создана целая система новодельных фетишей, в качестве которых могут выступать деньги (которые приобрели универсальную знаковую природу и способность замещать многие образы и репрезентовать многие типы человеческих отношений), различные товары массового потребления, коммерческая реклама и т. д. (Это сопрягается, в частности, с концепцией «товарного фетишизма», впервые сформулированной К. Марксом: Маркс писал, что в религиозной сфере «продукты человеческого мозга представляются самостоятельными существами, одарёнными собственной жизнью, стоящими в определённых отношениях с людьми и друг с другом. То же самое происходит в мире товаров с продуктами человеческих рук. Это я называю фетишизмом, который присущ продуктам труда, коль скоро они производятся как товары, и который, следовательно, неотделим от товарного производства» [14, с. 71]). Овеществляемость всего (включая память и впечатления), подкреплённая сужением духовной сферы культуры, стала одним из основных симптомов модернизационных процессов. В этом плане вполне отчётливо проявляется логика широкого распространения сувенирной продукции, которая «симулирует в пластмассе» различные грани реальности и в определённой мере компенсирует бедность духовной сферы общества потребления посредством множества ассоциаций, напоминаний и аллюзий к личному опыту владельцев. Холодильник, украшенный магнитами, стал для весомого числа наших современников своеобразным «алтарём» или «витриной личного опыта».

Представляется, что сувенирная продукция в очень большой степени служит именно для восполнения духовных лакун культуры, образовавшихся в Новейшее время. Предмет с сильной ценностно-смысловой гравитацией обладает симулятивными свойствами, возвращая, пробуждая и формируя мир ассоциаций и впечатлений, пережитых когда-то человеком. Указанное свойство приобретает высокую степень эффективности, если человек окружён комплексом артефактов, симулирующих определённую индивидуально пережитую реальность. А если учитывать, что игры воображения по поводу воспроизводства прошлого ведутся порой со значительной долей искажений и дополнений, сувениры могут становиться проводниками и в мир идеализированных впечатлений.

Если обратиться к частным сторонам влияния модернизации на рассматриваемую сферу, то необходимо отметить, что само существование феномена сувенирной продукции прежде всего связано с появлением массового производства, с самой возможностью очень быстро и задёшево создать множество одинаковых предметов (ещё 200 лет назад это было затруднительно). Распространение новых материалов (прежде всего пластмасс), создание конвейеров и автоматизированного производства существенно повлияли на специфику вещественного пространства массовой культуры, в том числе и на сувениры. Кроме того, на эволюцию рассматриваемого феномена очень существенное влияние оказало развитие кино-, фото- и видеоиндустрии, развитие 
медиасферы; в конце XX в. - появление Интернета и принципиальные изменения во всем, что связано с обработкой, хранением и передачей информации.

Многие стороны изучаемого явления на инструментальном уровне определяются психоэмоциональными и поведенческими аспектами массового потребителя. Так, одной из специфических черт современного потребления является «удовольствие небольших растрат», «удовольствие от ощущения себя \$-убъектом» [4, с. 43]: покупая, человек получает удовлетворение, реализуя свою «состоятельность», приобщаясь к социуму и локации; это, естественно, распространяется и на покупку сувениров. Другим аспектом изучаемой темы является стремление человека «документировать» свою жизнь через подтверждение присутствия в тех или иных местах; особенно ярко эта тенденция стала проявляться в период распространения массового туризма. Оптимальной формой материализации данных подтверждений стали сувениры и фотографии (примечательно, что оба этих продукта нередко сочетаются в рамках одного сувенирного изделия, несущего визуальный образ). Ещё одним примечательным аспектом является то, что сувенир, являясь в большинстве случаев достаточно дешёвым продуктом, стал внедряться в сферу подарков: человек, возвращаясь из путешествия, вместо индивидуально-подобранных «гостинцев» привозит серию недорогих типовых изделий, одаривая ими близких и знакомых, по сути, формализуя данный процесс. Кроме того, сувенир нередко становится основой дарений в рамках деловой культуры и повседневного общения между людьми; здесь же следует указать, что сувенир как форма подарка достаточно давно проявляет себя на уровне дипломатической культуры [см. об этом: 15, с. 10-16]; указанные свойства сувениров отражают их глубинные связи с феноменом дарений, интересовавшим таких учёных как М. Мосс, К. Леви-Стросс, Б. Малиновский и Й. Хейзинга. Устойчивость данной тенденции обеспечивается тем, что сувенир выступает формой материализации знаков внимания, во многом реализуя указанные выше архетипические стороны обеспечения связей между людьми. В данном случае показательно исследование Х. Уилкинса, согласно которому в США свыше 75 \% женщин и 60 \% мужчин покупают сувениры для будущего дарения [16, с. 91].

Достаточно примечательным фактором, который способствует популяризации сувениров в культурах, погруженных в процессы модернизации, являются процессы национального строительства, роста национального самосознания и «брендирования» наций. Многие народы и суперэтнические образования стали нуждаться в особых сферах закрепления национального самосознания, идеологии и идентичности посредством определённых аспектов традиционной культуры и соответствующих феноменов. В ходе национального строительства во многих культурах стали популяризироваться и массово производиться всевозможные артефакты, отражающие укоризненность и устойчивость фольклорных традиций, обеспечивающих историко-генетическую и межпоколенную преемственность указанных культур. Примером в данном случае может служить популяризация изделий Мстеры, Хохломы, Гжели, Палеха, Холуя, Жостова, оятской керамики, оренбургских платков и т. д. в конце XIX - начале XX вв. в Российской империи, а также в 19201930 гг. в ходе советского национального строительства. Указанные процессы, принимая формы соответствующих «гуманитарных технологий», находят своё проявление и в наши дни на уровне популяризации отдельных феноменов национальных и этнических культур, а также их комплексов, сопровождающих различные меры по национальному строительству. Показательным примером в данном случае является популяризация кокошников в России во время чемпионата мира по футболу 2018 г. Весьма распространённой формой воплощения отмеченных технологий является и сувенирная продукция.

Кроме того, тенденция акцентирования на традиционно-этнические и национальные аспекты культуры находит своё продолжение и усиление в контексте развития индустрии туризма и межкультурных контактов на уровне брендирования нащиональнылх культур. Брендируются не только нации, но и города (Петербург, Венеция), регионы, отдельные объекты (замки и пр.). Сувенир в данном случае выступает одной из самых важных составляющих популяризации национального колорита, оказывая влияние как на внешнего, так и на внутреннего потребителя. Причём параметры влияния данных изделий на потребителя могут быть разными: от обеспечения вполне 
корректной трансляции культуро-генетического опыта, эффективного национального строительства и повышения уровня этнокультурной грамотности массового потребителя до провоцирования культуро-генетических разрывов и искажения «наследственного материала» культуры - что рождает ряд проблем, связанных, помимо прочего, со сложностью экспертной оценки данной продукции и недостаточной изученностью её техногуманитарного потенциала.

Необходимо указать, что сфера этнотрадиционных сувениров, отражая указанные выше тенденции, является неоднородной. Речь идёт о различных пропорциях соотношения «высококачественной» сувенирной продукции, близкой к аутентичным «первообразам», и недорогих поделок, которые лишь отдалённо имитируют или достаточно сильно искажают оригиналы, что порой весьма остро и болезненно проявляется при тиражировании сакральных аспектов культуры. Соответственно, граница между корректно воспроизведённым в качестве сувенира этнокультурным артефактом и его неудачной репликой носит нечёткий характер, рождая массу переходных форм между двумя указанными полюсами. При этом на стадии формирования массовой культуры, в конце XIX-первой половине XX вв., роль сувениров зачастую выполняли традиционноремесленные изделия, выпускаемые артелями, небольшими предприятиями, отдельными кустарями. Данные изделия так или иначе имели отличия от «первообразов», бытующих в традиционной культуре, но эти отличия во многих случаях были минимальны. Однако с течением времени баланс стал смещаться в сторону фабричной продукции, зачастую дешёвой и низкокачественной (хотя сувениры близкие к «первообразам» производят и в наше время).

Возвращаясь к основной линии исследования, отметим, что практически с самого появления сувениров как массового феномена в различных культурах имело место масштабное использование сакральных образов, символов и артефактов. Это во многом связано с тем, что во второй половине XX в. повсеместно произошёл всплеск массового (и порой поверхностного) интереса к культурам различных этносов, регионов, стран, вызванный, помимо прочего, частичным преодолением европоцентризма. Факторами, которые спровоцировали данный интерес, стали рост туристического сектора культурных индустрий, а также насыщение соответствующей информацией коммуникативного пространства мировой культуры.

Сам феномен «сувенир» в сознании многих людей имеет теснейшую связь с таким явлением как «туризм»; примечательно в данном случае то, что этимологически «сувенир» во французском языке буквально означает «то, что привезено из пути». В результате указанной близости практически произошло «сращивание» сувенирной отрасли с туристическим сектором, что повлекло «традицию» приобретения сувениров как непременного атрибута путешествий - что вызвало соответствующие трансформации и самой сувенирной продукции. Большая часть сувениров представляет собой небольшие дешёвые изделия; они имеют «очень умеренную дозу аутентичности», «серийно-нейтральны» и нередко функциональны. Как следствие, продукция, отражающая этнотрадиционные аспекты многих культур, зачастую транслирует не местный колорит, а то, что турист готов принять за него [4, с. 39]. Исследователь указанного вопроса М.А. Корецкая отмечает, что в рамках реализации отмеченных тенденций «тщательно фильтруются, упрощаются и стандартизируются используемые образы. На изображениях человеческие лица и тела приобретают каким-то неуловимым образом европеоидные черты $<\ldots>$ Не говоря уже о том, что для тиражирования выбираются сюжеты, которые поверхностным туристом могут быть прочитаны как в целом понятные и жизнеутверждающие. К примеру, на сувенирных египетских папирусах часто можно увидеть всевозможных кошек (символизирующих домашний уют), скарабеев (в качестве талисманов на счастье), Тутанхамона с женой (любовь и семейные узы) и гораздо, гораздо реже ритуал мумификации или отверзания уст» $[4$, с. 40$]$.

Продолжая рассматривать тему низкого уровня этнокультурной грамотности массового потребителя, остановимся на некоторых вопросах, имеющих отношение к культуре потребления сувенирной продукции. В настоящее время остро проявляется проблема расхищения культурного наследия многих стран и регионов посредством его самовывоза на сувениры. Так, из Республики Алтай туристы вывозят наскальные рисунки (петроглифы), легко откалывая их от слоистой 
горной породы; кроме того, вывозят и балбалы - каменные статуи. При этом многие туристы даже не представляют, с чем связаны все эти артефакты и какую сакральную роль они играют для местных жителей. Примеров подобного незнания и неграмотности можно привести достаточно много, что проявляется и на поведенческом уровне, например в случае с подвязыванием ленточек на деревья - обрядом, который на Алтае совершается в сакральных местах (например, на перевалах) на новую луну и олицетворяет подношения духам, хозяевам, предкам в знак почтения и благодарности (исторически бытовавшие у алтайцев представления о природе и в частности о сакральных локациях описывает, например, исследователь И. А. Жерносенко [17]). Указанный обряд туристы «совершают» там, где им заблагорассудится и любое удобное им время; причём вместо ленточки порой используются полотенца, ремни, носки, в период пандемии коронавируса - также медицинские маски. Подобное поведение порой воспринимается местными жителями болезненно. Отметим также, что историко-культурное наследие региона представляет исключительную научную ценность [18, с. 45-64]. В этой связи следует сказать о положительных сторонах распространения массовых сувениров - оно позволяет заполнить лакуну потребления памятных вещей и отвлекает потребителя от стихийного (и порой варварского) сбора культурного наследия Алтая на «сувениры».

Переходя к рассмотрению примеров этносувенирной продукции, воспроизводящей сакральные феномены культуры, необходимо напомнить, что ситуация внутреннего бытования ценностно-смыслового поля культуры бывает неоднозначной, в результате чего её носители могут воспринимать по-разному как традиции, так и ценностно-смысловые «константы» собственной культуры, включая её сакральную сферу, особенно с учётом её историко-генетических преобразований (например, как в случае с расколом на «домодерновое» и «модерновое» состояния культуры). Кроме того, следует помнить, что носители разных культур порой не воспринимают аксиосферы других культур близко к сердцу, даже имея некоторые знаниях об этих культурах. Также аксиосфера может не восприниматься в силу полной этнокультурной безграмотности потребителя, либо неприятие некой аксиосферы с его стороны может носить осознанный характер. Вследствие указанной сложности «чистые» и однозначные примеры удачного и неудачного использования сакральных аспектов культур в сувенирной продукции выделить достаточно трудно.

Показательным примером воспроизводства сакральных аспектов традиционных культур являются уже упомянутые выше сувениры, отражающие магические и шаманские культы, включая атрибутику осуществления соответствующих обрядов. Отдельную группу примеров в данном случае представляет сувенирное воспроизводство ритуальных масок, сакральная составляющая которых практически не воспринимается современным потребителем. Показательно в данном случае исследование В. В. Подмаскина, который, изучая на примере Дальнего Востока России процесс превращения обрядовой маски в предмет художественного ремесла и сугубо эстетического воздействия на человека, отмечает: «Используя народный технический и художественный опыт, мастера-надомники создают художественные произведения с изображением на них маскеток, которые используются как украшения одежды, кулоны, преподносятся в качестве подарков, служат символом этнической принадлежности, отражают стилевые особенности художественной культуры. Среди ремёсел этносов региона преобладают художественные промыслы с современными формами их организации. Маски-личины, полностью утратившие первичную обрядовую функцию, стали предметами декоративно-прикладного искусства, часто сувенирного характера» [19, с. 178]. Тем не менее, даже в наше время среди представителей многих этнических культур сохраняется трепетное отношение к аутентичным предметам магического и шаманского культов, что способствует неодобрению с их стороны «профанного» тиражирования подобных артефактов либо их элементов.

Другим примером является тиражирование шаманских бубнов во всевозможных сувенирных модификациях. Так, в сувенирных лавках, расположенных на Чуйском тракте (Республика Алтай), встречаются уменьшенные «копии» шаманских бубнов с нанесёнными на них изображениями медведей, волков, гусей, маралов, рыб и т. д.; данные образы являются плодом фантазии их 
авторов и противоречат традициям алтайцев. Чаще всего при нанесении на сувениры образов, узоров и различных знаков изготовители стараются выдерживать стиль наскальных рисунков и рунической письменности - для создания иллюзии аутентичности, для того, чтобы изделие вызывало у покупателей ассоциации с древностью и таинствами. Встречаются и сугубо натуралистичные изображения тех или иных животных. Но важно помнить, что перед покупателем не просто ударные инструменты, пусть даже и с украшениями, а бубны, которые люди «знающие», посвящённые в Традицию, называют «нерабочими». Иными словами, после проведения определённых процедур на этих бубнах можно проводить шаманское камлание (или имитировать его). Однако требуемые обряды при изготовлении бубна не соблюдаются (порой потому, что производитель попросту не знает об их необходимости и их «регламенте»). Кроме того, искажения касаются и технических аспектов воспроизводимых артефактов. В частности, не соблюдается ритуальная часть при поиске и получении самого материала для изготовления обода и мембраны бубна: не учитываются лунно-календарные особенности, место произрастания дерева, не соблюдаются предписанные условия умерщвления животного и выделки его шкуры [О порядке изготовления бубна, исторически принятом у алтайцев, см.: 20, с. 159-203; 21, с. 49-64].

Исследователи шаманизма однозначно отмечают, что бубен - это главнейший атрибут шамана; без него шаман - не шаман. Изучая обряды коренных народов Сибири, можно выделить множество общих черт в обрядах и в атрибутах, используемых при их проведении; к таким атрибутам относятся, помимо бубна, комус (варган), колотушка бубна, колокольчики, различные обвесы на бубне, шаманское облачение и пр. И все эти предметы мы наблюдаем в сувенирных лавках на Алтае - на берегу Телецкого озера, у источника Аржан-Суу, на перевалах Семинский и Чике-Таман и во многих других местах, которые и в наши дни почитаются алтайцами как сакральные и в которых совершаются традиционные обряды. Интернет пестрит предложениями о продаже бубнов для «практических» целей; будучи популярным феноменом современной культуры, бубны используются в качестве логотипов и товарных знаков; их образы, нередко далёкие от оригиналов, широко представлены в медиа-пространстве и в визуальной городской среде. Одни потребители покупают бубны для медитаций, иные - просто в качестве музыкального инструмента, третьи видят в них экзотические сувениры. «Инструменты», некогда наводившие на носителей определённых культур ужас, в наше время стали предметами потребления, доступными в любой форме, любом формате, любом количестве... Вследствие отмеченных отклонений указанные изделия, напоминающие об этнотрадиционном прошлом, могут восприниматься как «тень», «отголосок» минувшего - с утратой сакральных аспектов. Можно предположить, что шаманский бубен, произведённый с отклонением от историко-культурного «канона» и в сувенирных формах, может восприниматься как «опустевший» в сакральном плане предмет, лишь указывающий на существование могучих оригиналов, к которым в традиционном обществе даже прикасаться было опасно. Всевозможные отклонения от канона, например от аутентичных изображений, могут представлять собой своеобразное оправдание права отдалённых копий на существование. Соответственно, пройдя через фильтры масс-культовых упрощений, артефакт, напоминающий о сакральном, может восприниматься как нечто приемлемое, допустимое - вследствие наличия дистанции с аутентичным. Представители многих культур относятся к таким копиям-сувенирам как к чему-то легитимному, хотя и не вполне желанному, именно вследствие слабой степени соответствия подлинности, понимая, где аутентичный предмет, а где его имитация. Однако парадокс заключается в том, что отклонение от оригинала может отрицательно воздействовать на потребителей данной продукции (как на межкультурном, так и на внутрикультурном уровне), искажая их представления о прошлом. Кроме того, необходимо помнить о том, что часть носителей тех или иных культур воспринимает отдалённые и некачественные копии сугубо отрицательно - именно вследствие их поддельности, отступления от канона и вторжения в сферу сакрального.

Среди других примеров тиражирования различных аспектов шаманской обрядности можно отметить реализуемые в Республике Алтай веера в виде перьев птиц, а также не имеющих отношения к культуре алтайцев «ловцов снов». При этом продавцы такой продукции порой указывают, 
что «ловцы» удерживают хорошие сны, а плохие пропускают, что является полным заблуждением. Также в качестве примера можно привести изготавливаемые с нарушением технологий топшуры (щипковый музыкальный инструмент), которые имеют сакральное значение для алтайцев; данные нарушения упрощают и занижают значение инструментов по сравнению с их изначальным статусом. Кроме того, для современной массовой культуры, в том числе и сувенирной отрасли, характерно использование значимых и «сильных» образов культуры Алтая, например образов шамана и охотника - хозяина тайги. Практика представлений с ряжеными «шаманами» и сувениры в виде трофеев диких животных, изначально связанных с хозяином тайги, не вызывает одобрения местного населения, поскольку сакральный статус данных образов не предполагает их повседневного использования для повышения зрелищности и привлекательности товара.

Изучение рассматриваемого вопроса показывает, что большая часть воспроизводимых в сувенирной продукции сакральных аспектов культуры относятся к «домодерновым» этапам культурогенеза тех или иных культур, что демонстрирует важность временной дистанции между бытованием того или иного артефакта в качестве сакрального и его воспроизводством на «профанном» уровне. Как следствие, сувенирные лавки наиболее ярко позиционируют артефакты, имеющие отношение к языческим этапам культурогенеза (например, турецкие «назары»-амулеты, предохраняющие от сглаза). Конечно, сувениры воспроизводят (хотя и несколько реже) и религиозные сакральные артефакты, однако это касается не всех религиозных традиций; в качестве примера можно привести японские амулеты «омамори».

Кроме того, важно затронуть такую грань рассматриваемой проблематики как тиражирование традиций, включая их сакральные компоненты, во взаимодействии с инновационными процессами. К сожалению, в изучаемой сфере доминируют инновационные воздействия на сувенирную этнотрадиционную продукцию, которые увеличивают дистанцию между ней и аутентичными образцами, приумножая прецеденты некорректного использования сакральных аспектов культуры. Показательным примером, имеющим отношение к тиражированию «мирского сакрального», является продуцирование на сувенирах советской символики в угоду массовому (преимущественному западному) потребителю, которое с точки зрения многих российских граждан порой принимает характер неуважительной и тенденциозной интерпретации образов и символов, имеющих отношение к советской истории. Стоит заметить, что в разных культурах государственная символика (и в частности символика армии и флота) имеет разный статус. И если для граждан отдельных западных стран нанесение изображения государственного флага на предметы одежды, которые имеют отношение к телесному низу (например, дамские купальники) представляется вполне приемлемым, то в России отношение к этой практике весьма неоднозначное, а у многих граждан откровенно неодобрительное. Подобное отношение также вызывают, к примеру, банные атрибуты с символикой Красной Армии; сувенирные шапки-ушанки «неорганичных» для этих изделий цветов (розового, салатового) с кокардами Советской Армии; матрёшки, содержащие карикатурные и гротескные образы советских и российских лидеров и т. п. продукция, заполонившая сувенирные лавки городов Российской Федерации, особенно часто посещаемых иностранными туристами.

Тем не менее, ориентируясь на внутреннюю сложность указанной сферы, уместно указать на ряд положительных примеров, показывающих, что возможно адекватное и бережное использование потенциала сувенирного тиражирования для сохранения и популяризации этнотрадиционных основ культуры, включая её сакральные составляющие. Так, в Республике Саха (Якутия) при производстве современной фарфоровой посуды нередко используют формы её деревянных, берестяных и кожаных этнотрадиционных аналогов, наделённых сакральной составляющей (например, чоронов), что позволяет вполне гармонично сочетать традиционные и инновационные аспекты культуры. Ещё одним примером, имеющим частный характер, является изготовление якутских традиционных украшений, имеющих сакральную (в том числе обереговую) природу не из серебра, которое является наиболее желательным металлом для создания подобного рода артефактов; тем не менее, если данное изделие выполнено из латуни, меди или мельхиора, 
но местным мастером и по аутентичным технологиям, то его ношение с точки зрения носителей якутской традиционной культуры вполне приемлемо. Заслуживает упоминания и практика изготовления якутскими школьниками сувенирных кукол в виде различных героев якутского эпоса Олонхо [22, с. 47]. Нередко сакральные орнаменты отражаются в сфере современной моды, достаточно удачно вплетаясь в инновационные процессы; здесь будет уместно сослаться на деятельность Театра костюма и пластики (г. Элиста, Республика Калмыкия), транслирующего этнотрадиционные аспекты калмыцкой культуры с учётом реалий современности.

Ярким примером, который высвечивает проблему трансляции сакрального во взаимодействии с инновационными процессами, являются изменения, коснувшиеся отечественных лаковых промыслов в начале XX века. Дело в том, что лаковой миниатюре Холуй, Палех и Мстера в том распространённом виде, к которому мы привыкли,-чуть менее столетия. Черные шкатулки из папье-маше с сюжетами из лубка, сказок Пушкина, картин Васнецова, пейзажами средневековых русских городов, романтизированными сценами крестьянского быта и праздников, тройками и т. д. - это советская инновация, направленная на сохранение промыслов, содержанием которых до революции было создание иконописных изображений. Так, парадоксально соединив в себе традиционное мастерство живописи с искусством создания бытовых предметов, пройдя через сложную метаморфозу утраты сакрально-религиозной компоненты, обусловленную советской идеологией, лаковая миниатюра обрела новое «сакрально-мирское» звучание маркера родной культуры и утилитарное назначение, которое стало «традиционным» и к которому все привыкли [23, с. 72]. Примечательно, что в наше время иконописная традиция данных промыслов получает импульс к возрождению.

При анализе изучаемой продукции важно помнить, что традиции и инновации находятся в постоянном взаимодействии; это же касается и некоторых трансформаций сферы сакрального, которая может изменяться, расширяться, несколько размываться и восприниматься по-разному в рамках различных эпох, поколений и социальных групп. Сакральное, как и многие другие компоненты культуры, не может быть абсолютно неизменным; достраиваясь и дополняясь, утрачивая одни аспекты и обретая другие, переходя из одной формы сознания в другую (в том числе и при переходе от религиозного к светскому, то есть «обмирщаясь»), сакральное сохраняется и в современных условиях, претерпевая трансформации, которые вполне уместно соотнести с архитектоническими процессами преобразования культурного наследия, фиксируемыми И. В. Кондаковым [24, с. 535]. В этом плане показательно, что многие актуальные в наше время инновации, возникшие в сфере русской традиционной культуры в Новое и Новейшее время, а также повлиявшие на неё извне, стали своеобразными маркерами национальной культуры, в том числе маркерами восприятия её сакральных аспектов с позиции сопричастности к ней, выражения чувства любви к Родине и патриотизма. С детства носители отечественной культуры приобщаются к таким феноменам как матрёшка; самовар; балалайка; русские сказки в интерпретации А. С. Пушкина, «вернувшиеся» в народную среду; песня «Из-за острова на стрежень» на слова Д. Н. Садовникова и песня «Ой, мороз, мороз» (законченный вариант которой связан с именем М. П. Уваровой), также ставшие «народными»; иллюстрации к русским сказкам, выполненные И. Я. Билибиным, дополнившие образы традиционного фольклора у современников и потомков; а также ко многим другим феноменам. Аналогичным образом обстоит ситуация и в других национальных культурах многие феномены, которые в настоящее время воспринимаются носителями этих культур как традиционные, «исконные», на самом деле возникли в XIX-XX вв.

Завершая анализ проблемы тиражирования сакрального в этносувенирной продукции, отметим, что в основе многих противоречий, вызванных данным явлением, лежат расхождения, связанные со столкновением разных картин мира и проблемой диалога между ними в современных условиях Многие способы отражения и объяснения реальности, которые сменяют друг друга в рамках отдельных культур и представляют историко-культурное многообразие человечества, могут иметь как точки соприкосновения, так и «точки противоречий». Культуры и их носители отличаются по форме выражения верований, пониманию сущности бытия и основных философских 
вопросов. Данные установки находят массу конкретных исторических выражений на уровне картин мира, многие из которых бытуют и в наши дни, вступая во взаимодействие и порой не находя общего языка. Научная картина мира - это явление относительно молодое; наряду с ней существует масса иных способов объяснения сути мироздания, и для многих культур эти способы являются более актуальными, чем естественнонаучная картина мира. По умолчанию каждая картина мира позиционирует себя как состоятельную, и многие механизмы взаимодействия между культурами на уровне картин мира сводятся в лучшем случае к молчаливому соседству и принятию друг друга на уровне допущения существования иного. При этом ситуация понимания «своего» как «правильного» явно или латентно расставляет в сознании носителя культуры иерархию картин мира с точки зрения их истинности. Указанный фактор, подкреплённый тем, что все приведённые выше способы отражения реальности находят своё проявление в современных условиях, невероятно усложняет взаимодействие между разными картинами мира, особенно на уровне сакральных аспектов; это оказывает влияние и на изучаемую сферу.

Таким образом, анализ заявленной темы показывает, что она представляет сложную сферу, в отношении которой нужен грамотный и взвешенный подход и которую нельзя оценивать однозначно. Указанная ситуация открывает целую нишу для развития проектно-методологической основы теории сувенира и соответствующей экспертизы, призванной давать оценку и рекомендации к производству и распространению сувенирной продукции, отражающей сакральные аспекты культуры. «В данной ситуации свой экспертный (как минимум на рекомендательном уровне) и технологический потенциал вполне способна проявить культурология, одной из задач которой является изучение различных механизмов сохранения и трансляции культуры, включая глубинные механизмы передачи и коррекции «культурного генома» в контексте современных процессов унификации культур» [25, с. 38]. Речь идёт о построении экспертных мнений с позиций оценки таких технических параметров как материал (аутентичный или нет), технология создания, форма, семантическая нагрузка, цветовое, звуковое, ароматическое и тактильное решения, авторство, связь с культурогенетическими напластованиями и др. Также необходимо учитывать фактор соответствия инноваций, вторгающихся и порой удачно интегрирующихся в сферу этнотрадиционных сувениров. На этом основании в данном ряду необходимо выделить достаточно субъективные маркёры, такие как соответствие «образу мира» (с присущим пространственно-временным гештальтом, образными решениями, формами и т. д.). Наконец, и это главное, необходимо учитывать соответствие указанной продукции ценностно-смысловой и ментальной сфере культуры, с учётом её архитектонических преобразований во времени, включая современное состояние.

\section{Список литературы}

1. Леонов, И. В. Этно-традиционный сувенир в пространстве массовой культуры / И. В. Леонов, В. Л. Соловьёва // Вестник Санкт-Петербургского государственного института культуры. - 2019. - № 1. C. $93-98$.

2. Быстрова, Т. Ю. Необходимые характеристики образа в дизайне сувенирной продукции // Академический вестник УралНИИпроект РААСН. - 2015. - № 1. - С. 91-97.

3. Рябова, И. А. Словарь международных туристских терминов (русско-английско-французсконемецкий) / И. А. Рябова, Д. К. Исмаев, С. Н. Путилина. - Москва : Книгодел, 2005. - 466 с.

4. Корецкая, М. А. Сувенир // Вестник Самарской гуманитарной академии. - 2008. - № 1. C. $38-43$.

5. Информационно-семиотическая теория культуры: введение : [моногр.]/Х. Г. Тхагапсоев, О. Н. Астафьева, И. И. Докучаев, И. В. Леонов. - Санкт-Петербург : [Б. и.], 2020. - 208 с.

6. Быстрова, Т. Ю. Сувенир как элемент корпоративной культуры и бизнескоммуникации // Человек в мире культуры. - 2013. - № 3/4. - С. 41-50.

7. Акинфеева, И. И. Сувенир как феномен культуры: специфика и классификационные признаки / И. И. Акинфеева, О. Е. Железняк // Вестник Иркутского государственного технического университета. - 2015. - № 5. - С. 305-313.

8. Даркевич, В. П. Аргонавты Средневековья. - Москва : Книжный дом «Университет», 2005. 256 c. - (Золотой запас знаний). 
9. Энциклопедия эпистемологии и философии науки / [редкол. : И. Т. Касавин (гл. ред. и сост.) и др.]. - Москва : Канон+, 2009. - 1248 с.

10. Культурология : энцикл. : [в 2 т.] / гл. редактор С. Я. Левит. - Москва : РОССПЭН, 2007. 1184 c. - (Summa culturologiae / Центр гуманитарных науч.-информ. исслед. Ин-та науч. информ. по общественным наукам Рос. акад. наук).

11. Атеистический словарь / [А. И. Абдусамедов, Р. М. Алейник, Б. А. Алиева и др.; под общ. ред. М. П. Новикова]. - 2-е изд., испр. и доп. - Москва : Политиздат, 1985. - 512 с.

12. Словарь иностранных слов современного русского языка / [сост. : Т. В. Егорова]. - Москва : Аделант, 2012. - 799 с. : ил.

13. Юнг, К.-Г. Об архетипах коллективного бессознательного // Вопросы философии. - 1988. - № 1. C. $133-152$.

14. Маркс, К. Капитал : [в 3 т.]. - Москва : Политиздат, 1983. - Т. 1. - 640 с.

15. Попов, А. Д. Символический дарообмен в советской культурной дипломатии периода холодной войны (на материале зарубежного туризма) // Управление в современных системах. - 2017. - № 4. C. $10-16$.

16. Кузнецова, В. Ю. Дизайн сувенирной продукции для историко-религиозного объекта: на примере Далматовского монастыря // Академический вестник УралНИИпроект РААСН. - 2016. - № 3. - С. 90-94.

17. Жерносенко, И. А. Метафизика Алтая: от сакрального ландшафта к ноосферной цивилизации : [моногр.]. - Барнаул : Изд-во Алт. гос. ин-та культуры , 2019. - 307 с.

18. Жерносенко, И. А. Культура Сибири и Алтая : [моногр.] / И. А. Жерносенко, Е. И. Балакина. Барнаул : Изд-во Жерносенко С. С., 2011. - 208 с.

19. Подмаскин, В. В. Маски коренных народов Тихоокеанской России // Россия и АТР. - 2019.№ 2. - C. $165-183$.

20. Потапов, Л. П. Алтайский шаманизм. - Ленинград : Наука : Ленингр. отд-ние, 1991. - 319 с.

21. Анохин, А. В. Материалы по шаманству у алтайцев, собранные во время путешествия по Алтаю в 1910-1912 гг. по поручению Русского комитета для изучения Средней и Восточной Азии : (Представлено в заседании Ист.-филол. отд. Акад. наук. 16 янв. 1913 г.). - [Ленинград : Рос. акад. наук], 1924. - [4], VIII, 248, IV c. : ил. - (Сборник музея антропологии и этнографии при Российской академией наук ; T. 4, 2).

22. Игнатьева, Е. Н. Якутский эпос Олонхо в творческой деятельности школьников // В мире науки и искусства: вопросы филологии, искусствоведения и культурологии. - 2015. - № 2. - С. 45-49.

23. Махлина, С. Т. Палех вчера и сегодня // Петербургские искусствоведческие тетради : [период. сб. тр. по истории искусства]. - Санкт-Петербург : Ассоциация искусствоведов, 2017. - Вып. 43. - С. $70-85$.

24. Кондаков, И. В. Архитектоника культурного наследия // Культурогенез и культурное наследие / науч. ред. и сост. А. В. Бондарев. - Москва : Центр гуманитарных инициатив ; Санкт-Петербург : Центр гуманитарных инициатив, 2014. - С. 533-544.

25. Улинова, И. Х. Значение культурных индустрий в сохранении этнического своеобразия калмыков // Вестник Санкт-Петербургского государственного института культуры. - 2019. - № 2. - С. 34-39.

Ivan $\boldsymbol{V}$. Leonov, Dr. of Cultural Studies Saint-Petersburg State Institute of Culture (Saint-Petersburg, Russia) ivaleon@mail.ru

Igor $V$. Kirillov

Saint-Petersburg State Institute of Culture (Saint-Petersburg, Russia) os84@yandex.ru

Artyom O. Piyantinov

Tomsk State University (Tomsk, Russia), Karakol Valley Council (Gorno-Altaysk, Russia) piyantinov87@mail.ru

\section{ISSUES OF SOUVENIR REPLICATING OF SACRAL CULTURAL ARTIFACTS}

Abstract. The paper analyses current practice in manufacturing and distributing souvenir items based on exploitation of sign and symbolic track of sacral artifacts from various ethnic cultures. Authors notice some positive and negative aspects of making souvenirs that are by nature of constructional copies 
of artistic forms embody meanings took from a symbolic core of sacral objects. Also, the paper gives a brief review of evolution of souvenir production industry since the $19^{\text {th }}$ century till now. Authors' opinion on a place of a souvenir in day-to-day culture, mass culture, and touristic sphere is expressed. Specifics of a traditional ethnic souvenir is explained.

Keywords: an artifact, sacral, souvenir, world view, culture genesis, cultural heritage, an archetype.

УДК $130.2(4 / 5)$

DOI: $10.32340 / 2414-9101-2020-3-33-39$

3. П. Морохоева, доктор философских наук, профессор Варшавский университет (Варшава, Польша) dharma1710@gmail.com

\section{ЕВРАЗИЯ И ВЗАИМОДЕЙСТВИЕ ЦИВИЛИЗАЦИЙ И КУЛЬТУР}

Аннотация. Представлен этимологический анализ дефиниции «Евразия»; охарактеризованы смысловые оттенки термина, приобретаемые им в зависимости контекста употребления: в философском дискурсе, географической науке, политической мысли, литературе. Охарактеризованы взгляды виднейших теоретиков евразийства - религиозного философа и историка Л. П. Карсавина (1882-1952 гг.), этнолога и философа Л. Н. Гумилёва (1912-1992 гг.) - на равноправный межцивилизационный диалог как базовый фактор культурного сближения этносов евразийского макрорегиона; раскрыта специфика рецепции классического наследия евразийцев в трудах современных российских исследователей - в частности, философа и синолога В. В. Малявина (род. в 1950 г.), рассматривающего евразийский проект как гармоничный сплав элементов русской и дальневосточной цивилизаций.

Ключевые слова: Евразия, евразийство, консубстанциальность, реляиионизм, взаимодействие культур и иивилизаций, «Я и Другой», диалогическое отношение, Л. П. Карсавин, Л Н. Гумилёв, В. В. Малявин.

В современном глобализированном мире возникает острая потребность разработки адекватных до изменившихся условий средств для межцивилизационной коммуникации. Прежде всего, это необходимо для регулирования социальных очагов нестабильности, конфликтов, возникающих то и дело в разных уголках планеты. Сложности, возникающие при этом, связаны с тем, что природа межцивилизационной коммуникации обусловлена многообразием культур и цивилизаций. Когда взаимодействуют культурные миры с разными ценностями, нормами, традициями, то в процессе коммуникации их представителей выплывает множество стереотипов, предвзятости как результат взаимного непонимания. Необходимо искать средства, позволяющие преодолевать барьеры коммуникации.

Важной чертой культурной глобализации является интенсификация коммуникации между человеческими сообществами на основе информационных технологий, миграций (легальных и нелегальных) людей в мире. Взаимодействие культур происходит посредством наложения контекстов носителей разных культурных традиций, благодаря создающейся таким образом открытости «инокультурным» образцам, а также посредством распространения массовой культуры. Эти контексты делают все более проницаемыми территориальные границы, размывают культурные традиции. Детерриторизация, внеисторичность, полицентризм, релятивизм характеризуют культурную глобализацию. 